\title{
Study on co-pyrolysis behavior of Shengli lignite and cron staw
}

\author{
Liang $\mathrm{Li}^{1}$, Muxin Liu ${ }^{1, *}$, and Yingyue Qin ${ }^{1}$ \\ ${ }^{1}$ School of Materials and Chemical Engineering, Bengbu University, 233030 Bengbu, Anhui Province, PR China
}

\begin{abstract}
The co-pyrolysis performance of coal and biomass was studied and the influences of corn straw on Shengli lignite pyrolysis were discussed in this paper. The results show that corn straw has much higher activity and lower char yield than Shengli lignite during pyrolysis process. Release of moisture in blends were more occur than individual pyrolysis of Shengli lignite and corn straw. Weight loss of experimental value was lower than that of calculated value in blends. The pyrolysis process of Shengli lignite was remarkably affected by adding corn straw. There exists positive synergistic effect between Shengli lignite and corn straw in co-pyrolysis process. Corn straw could reduce the pyrolysis activation energy of SL dramatically above $350^{\circ} \mathrm{C}$.
\end{abstract}

\section{Introduction}

Energy supply is an important issue of economic development for China. Coal is the most abundant fossil fuel in China ${ }^{[1]}$. Reserve of lignite accounts for about $13 \%$ of the total coal reserves. Besides, there are abundant biomass wastes resources in China, such as agricultural residues. Adequate utilization of them were consistent with national energy policy to compensate for the petroleum and gas resources relative insufficiency situation $^{[2]}$.

At present, pyrolysis is one of the clean and efficient approach to utilize low-grade coal and biomass resources. Generally, biomass has high pyrolytic performance as a result of hydrogen content and oxygen content. Thermal conversion of coal combined with biomass for mild reaction conditions to take advantage of biomass. The mechanism of co-pyrolysis between coal and biomass has remained still elusive in the current literature ${ }^{[3]}$.

Since the 1980s, Robert et al. ${ }^{[4]}$ found that lignin could promote coal pyrolysis at $300{ }^{\circ} \mathrm{C}$ firstly, and believed that free phenolic radicals generated from lignin pyrolysis could induce the break of coal structure. Copyrolysis of bituminous coal and sawdust result in more yield of $\mathrm{CO}$ and $\mathrm{CH}_{4}$ than individual pyrolysis in fixed bed ${ }^{[5]}$. Haykiri found that there exist remarkably synergistic effect in co-pyrolysis of lignite and hazelnut shell, while not available situation for bituminous coal ${ }^{[6]}$. Cordero tested the co-pyrolysis process of biomass and high-sulfur coal at $600{ }^{\circ} \mathrm{C}^{[7]}$. Then they found better desulphurization effect had been obtained with adding biomass. Nevertheless, the Synergistic effect between coal and biomass is inexistence by some scholars, because of non-overlapping in pyrolysis range between coal and biomass. As a result, the fraction enriched in more hydrogen, originated from biomass pyrolysis, could not effectively react with coal ${ }^{[8,9]}$. The key issue of discussion on synergistic effect is overlapping area of pyrolysis range between coal and biomass.

In this work, co-pyrolysis behaviors of lignite and corn straw were investigated in a thermogravimetric analyzer. Further pyrolysis process is divided into three events in TG curve. The synergistic effects are described, combined with kinetics analysis of each events.

\section{Materials and Methods}

\subsection{Materials}

The feedstock lignite was from Shengli Coal Mine of Inner Mongolia Autonomous Region in China. The feedstock corn straw was from Linyi city, Shangdong province. The Shengli lignite (SL) and corn straw (CS) were ground to below $0.2 \mathrm{~mm}$, subsequently dried in a vacuum at $80{ }^{\circ} \mathrm{C}$ for $12 \mathrm{~h}$ before used. The proximate and ultimate analyses of SL and CS are listed in Table 1.

\subsection{Thermogravimetric analysis}

Pyrolysis of sample (including SL, CS and their blends) was performed in a thermogravimetric analyzer (Setaram TG-DTG type, France). About $10 \mathrm{mg}$ of sample was placed in alumina crucible and heated at the rate of 10 ${ }^{\circ} \mathrm{C} / \mathrm{min}$ under $50 \mathrm{ml} / \mathrm{min}$ nitrogen flow. The initial temperature and the termination temperature are $50{ }^{\circ} \mathrm{C}$ and $800{ }^{\circ} \mathrm{C}$, respectively.

\footnotetext{
* Corresponding author: liumx49@163.com
} 
Table 1. Proximate and ultimate analyses of SL and CS.

\begin{tabular}{|c|c|c|c|c|c|c|c|c|c|}
\hline \multirow{2}{*}{ Sample } & \multicolumn{4}{|c|}{ Proximate analysis (wt.\%) } & \multicolumn{4}{|c|}{ Ultimate analysis (wt.\%) } & \multirow{2}{*}{$\mathrm{H} / \mathrm{C}$} \\
\hline & $\mathrm{M}_{\mathrm{ad}}$ & $A_{d}$ & $\mathrm{~V}_{\text {daf }}$ & $\mathrm{FC}_{\text {daf }}$ & $\mathrm{C}_{\mathrm{daf}}$ & $\mathrm{H}_{\text {daf }}$ & $\mathrm{N}_{\text {daf }}$ & $\mathrm{S}_{\mathrm{t}, \mathrm{d}}$ & \\
\hline SL & 20.77 & 17.14 & 46.96 & 53.04 & 70.18 & 5.31 & 1.09 & 1.82 & 0.91 \\
\hline $\mathrm{CS}$ & 6.82 & 4.27 & 75.21 & 24.79 & 49.00 & 5.47 & 0.40 & 0.15 & 1.34 \\
\hline
\end{tabular}

ad: air dry basis; d: dry basis; daf: dry ash free basis; $\mathrm{S}_{\mathrm{t}, \mathrm{d}}$ : total sulfur on dry basis

\section{Results and discussion}

\subsection{Individual pyrolysis performance of SL and CS}

Observed individual pyrolysis perfirmances of SL and CS were demonstrated in Fig.1. The initial pyrolysis temperature of SL was $310^{\circ} \mathrm{C}$ and the temperature of the maximum weight loss rate appeared at $430^{\circ} \mathrm{C}$. The main pyrolysis temperature range of SL was $310{ }^{\circ} \mathrm{C}$ to $550{ }^{\circ} \mathrm{C}$. Unlike SL, the initial pyrolysis temperature of CS was $260{ }^{\circ} \mathrm{C}$ and the temperature of the maximum weight loss rate appeared at $320{ }^{\circ} \mathrm{C}$. The shoulder peak at $280{ }^{\circ} \mathrm{C}$ correspond to the thermal decomposition peak of hemicellulose ${ }^{[10]}$. The main pyrolysis temperature range of CS was $260{ }^{\circ} \mathrm{C}$ to $360{ }^{\circ} \mathrm{C}$. The pyrolysis temperature range of CS was significantly lower than SL, and that there was overlap of the pyrolysis temperature range between SL and CS. CS has much higher content of volatiles matter than SL during pyrolysis. In other words, CS has much higher activity than SL during pyrolysis process. Furthermore, it suggested that SL pyrolysis began while CS pyrolysis didn't finish, due to the overlapped area of the pyrolysis temperature range between SL and CS.

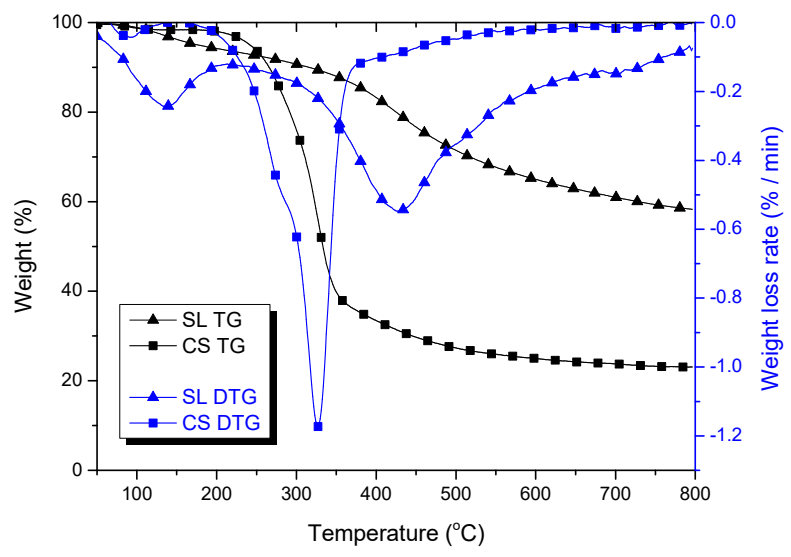

Fig. 1. TG and DTG curves of individual pyrolysis of SL and CS

\subsection{Co-pyrolysis performances of SL and CS blends}

In order to evaluate the co-pyrolysis performances of SL and CS blends, the investigation on the thermal behavior of mixed samples with different mixed rate of mass was employed. As shown in Fig.2, the weight loss of experimental value (Exp) between $50{ }^{\circ} \mathrm{C}$ to $200{ }^{\circ} \mathrm{C}$, corresponding to removal of moisture in blends, was higher than that of calculated value (Cal). Meanwhile, the char yield of Exp was lower than that of Cal below $600{ }^{\circ} \mathrm{C}$. It showed that co-pyrolysis generated less char generated with adding biomass in the blend.

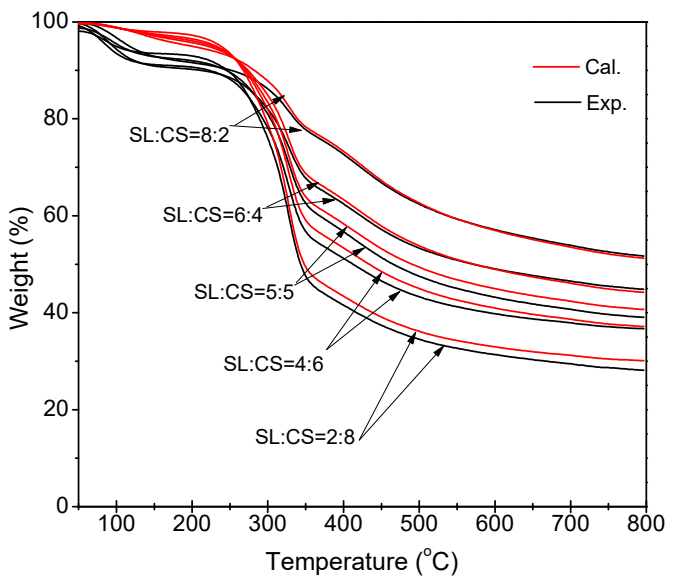

Fig. 2. TG curves of the blends pyrolysis with different ratio of SL and CS

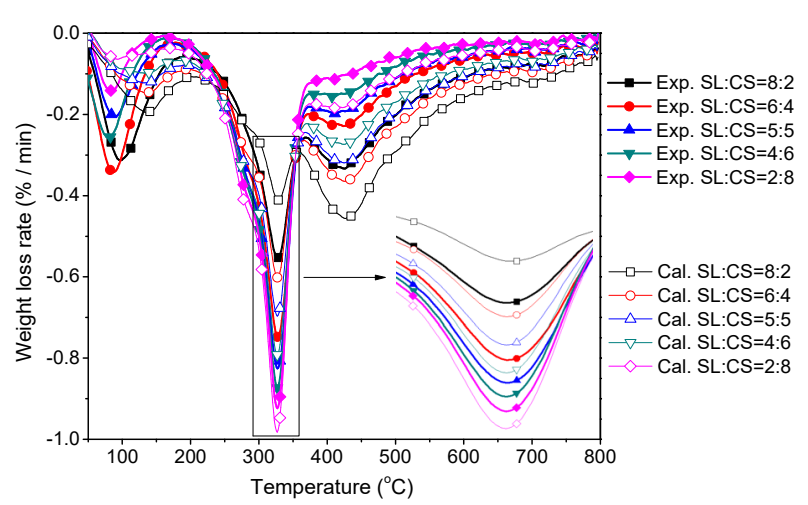

Fig. 3. DTG curves of the blends pyrolysis with different ratio of SL and CS

As can be seen from Fig.3, each blend maximum weight loss rate of Exp was higher than that of Cal at $325^{\circ} \mathrm{C}$, corresponding to $\mathrm{CS}$ pyrolysis, except the blend (SL:CS=2:8). Meanwhile, each blend weight loss rate of Exp was lower than that of Cal at $430{ }^{\circ} \mathrm{C}$, corresponding to SL pyrolysis. It suggest that the blends had proven more easily pyrolysis than anticipated. Besides, the pyrolysis performance of SL become better with adding amount of CS. The radical produced by pyrolysis of lignin in biomass could promote the pyrolysis of aliphatic structure in coal at relatively low 
temperature ${ }^{[11]}$. Such large amounts of aliphatic structure in SL can be induced to pyrolysis by radicals produced by CS pyrolysis. Simultaneously, rapid escape of volatiles in CS pyrolysis may accelerate the entrainment of volatiles in SL pyrolysis. That led to that the Exp result of maximum weight loss rate at $325{ }^{\circ} \mathrm{C}$ is generally higher than the Cal result and the Exp result of weight loss rate at $430{ }^{\circ} \mathrm{C}$ is generally lower than the $\mathrm{Cal}$ result. These results indicate that positive synergetic effect exists between SL and CS during co-pyrolysis.

\subsection{Kinetic analysis on co-pyrolysis behavior of SL and CS}

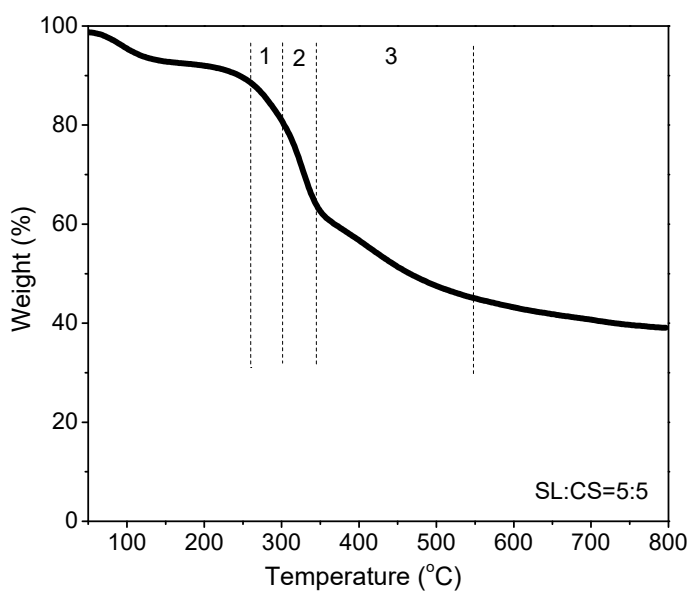

Fig. 4. Three pyrolysis events for a blend (SL:CS=5:5)
In order to further understand the synergetic effect between SL and CS during co-pyrolysis, a kinetic analysis has been performed for TG curves of blends. Coats-Redfern integral method is generalized to analysis on co-pyrolysis behavior of SL and $\mathrm{CS}^{[12,13]}$.

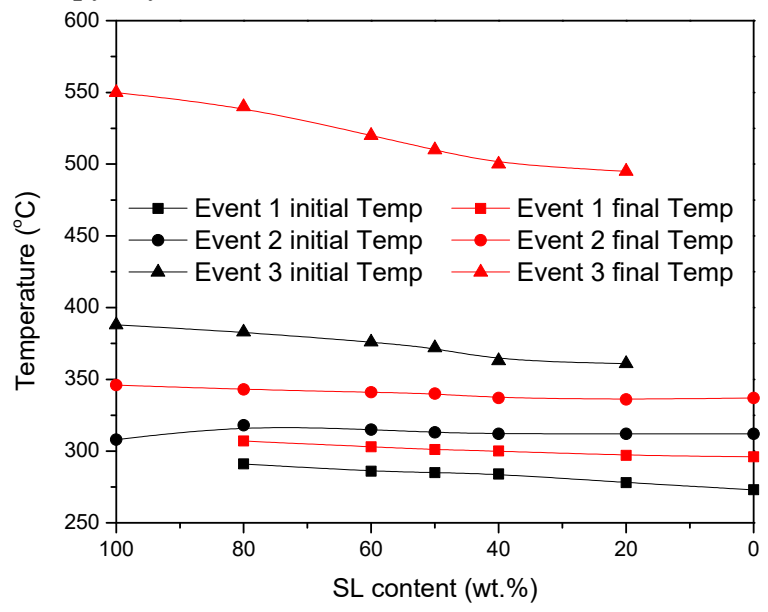

Fig. 5. Initial and final temperature of three pyrolysis events for all samples

According to TG curve, the weight loss of the blend below $150{ }^{\circ} \mathrm{C}$ belongs to a slow release of moisture in sample. This should not be counted in kinetic analysis. Meanwhile, to simplify the calculate process, the TG curve was divided into three successive stages between $250{ }^{\circ} \mathrm{C}$ to $550{ }^{\circ} \mathrm{C}$, based on the major slope change of the curve[14]. Fig.4 shows a typical three pyrolysis events cut from the curve of blend well (SL:CS=5:5).

Table 2. Kinetic parameters for the pyrolysis of SL, CS, and their blends.

\begin{tabular}{|c|c|c|c|c|c|}
\hline & SL:CS (wt./wt.) & $\begin{array}{c}\mathrm{Ea} \\
\left(\mathrm{kJ} \cdot \mathrm{mol}^{-1}\right)\end{array}$ & $\begin{array}{c}\mathrm{A} \\
\left(\mathrm{min}^{-1}\right)\end{array}$ & Fitting equation & $\mathrm{R}^{2}$ value \\
\hline \multirow[t]{6}{*}{ Event 1} & $8: 2$ & 18.93 & 1.24 & $y=-2277.29 x-9.8149$ & 0.9955 \\
\hline & $6: 4$ & 25.26 & 7.33 & $y=-3038.39 x-8.3297$ & 0.9984 \\
\hline & $5: 5$ & 32.61 & $4.19 \times 10^{1}$ & $y=-3922.79 x-6.8409$ & 0.9999 \\
\hline & $4: 6$ & 34.39 & $7.27 \times 10^{1}$ & $y=-4136.85 x-6.3444$ & 0.9995 \\
\hline & $2: 8$ & 43.79 & $6.37 \times 10^{2}$ & $y=-5266.42 x-4.4154$ & 0.9998 \\
\hline & $0: 10$ & 63.74 & $5.69 \times 10^{4}$ & $y=-7666.54 x-0.2985$ & 0.9989 \\
\hline \multirow[t]{7}{*}{ Event 2} & $10: 0$ & 11.96 & $1.49 \times 10^{-1}$ & $y=-1438.83 x-11.4757$ & 0.9960 \\
\hline & $8: 2$ & 30.5 & $2.19 \times 10^{1}$ & $y=-3668.84 x-7.4258$ & 0.9970 \\
\hline & $6: 4$ & 45.79 & $9.20 \times 10^{2}$ & $y=-5507.98 x-4.0922$ & 0.9989 \\
\hline & $5: 5$ & 55.12 & $7.40 \times 10^{3}$ & $y=-6629.29 x-2.1929$ & 0.9989 \\
\hline & $4: 6$ & 61.3 & $3.34 \times 10^{4}$ & $y=-7373.10 x-0.7911$ & 0.9991 \\
\hline & $2: 8$ & 73.61 & $5.00 \times 10^{5}$ & $y=-8853.86 x+1.7318$ & 0.9990 \\
\hline & $0: 10$ & 90.47 & $1.92 \times 10^{7}$ & $y=-10881.09 x+5.1716$ & 0.9994 \\
\hline \multirow[t]{4}{*}{ Event 3} & 10:0 & 38.15 & $6.26 \times 10^{1}$ & $y=-4588.63 x-6.5966$ & 0.9991 \\
\hline & $8: 2$ & 30.88 & $2.65 \times 10^{1}$ & $y=-3713.84 x-7.2438$ & 0.9990 \\
\hline & $6: 4$ & 28.29 & $2.52 \times 10^{1}$ & $y=-3402.89 x-7.2069$ & 0.9955 \\
\hline & $5: 5$ & 26.95 & $2.19 \times 10^{1}$ & $y=-3241.81 x-7.3013$ & 0.9940 \\
\hline
\end{tabular}


Fig.5 presents comparison of the initial temperature and final temperature of three pyrolysis events for all samples. As can be seen from Fig.5, event 1 initial temperature and event 3 initial temperature slightly reduced with decreasing SL content in blends. Event 1 final temperature, event 2 initial temperature, and event 2 final temperature had remained about the same value with decreasing SL content in blends. However, significantly reduce period of event 3 final temperature, associated with coal pyrolysis, was observed followed by a stable period with further decreasing SL content in blends. It demonstrated that event 1 and event 2 of SL pyrolysis should have been less affected by adding CS, but CS had great effects on event 3 of SL pyrolysis.

The results of the kinetic analysis for all sample are further listed in Table 2. The correlation coefficients of the fitting equation were above 0.99. It showed that linear regression theory used was reasonable and accurate. In event 1 and event 2, the SL pyrolysis had not yet happened because of the lower pyrolysis temperature. As a result, Ea values of event 1 and event 2 linearly increased with adding CS, respectively. In event 3 , Ea value rapidly decreased with adding CS. This indicated that CS could reduce the pyrolysis activation energy of SL in event 3, providing the evidence about the present of positive synergistic effects between SL and CS in pyrolysis process.

\section{Conclusion}

The co-pyrolysis of SL and CS were investigated. CS has much higher activity and lower char yield than SL during pyrolysis process. Release of moisture in blends were more occur than individual pyrolysis. Weight loss of Exp was lower than that of Cal in blends. The SL pyrolysis was affected by adding CS. There exists positive synergistic effect between SL and CS in copyrolysis process. CS could reduce the pyrolysis activation energy of SL above $350{ }^{\circ} \mathrm{C}$.

\section{Acknowledgments}

The authors gratefully acknowledge the financial support of the National Science Foundation for Cultivation Project of Bengbu University (Grants 2018GJPY02, 2018GJPY01), National Natural Science Foundation of China (Grant 21978003), the Opening Foundation of Anhui Province Key Laboratory of Coal Clean Conversion and High Valued Utilization (Grant CHV1905), and Scientific Research Foundation for Advanced Talents of Bengbu University.

\section{References}

1. L. Dong, S. Han, W. Yu, Z. Lei, S. Kang, K. Zhang, J. Yan, Z. Li, H. Shui, Z. Wang, S. Ren, C. Pan,
Effect of volatile reactions on the yield and quality of tar from pyrolysis of Shenhua bituminous coal, Journal of Analytical and Applied Pyrolysis, 140 (2019) 321-330.

2. H. Shui, D. Zou, H. Wu, F. He, X. Wang, C. Pan, Z. Wang, Z. Lei, S. Ren, S. Kang, C. Chunbao Xu, Coliquefaction of Xilinguole lignite and lignin in ethanol/water solvents under a cheap iron ore catalyst, Fuel, 251 (2019) 629-635.

3. Y. Li, S. Huang, S. Wu, Y. Wu, J. Gao, Copyrolysis of lignite and vacuum residue: Product distribution and hydrogen transfer, Fuel, 263 (2020) 116703.

4. R.W. Coughlin, F. Davoudzadeh, Lignin depolymerizes coal at $300{ }^{\circ} \mathrm{C}$, Nature, 303 (1983) 789-791.

5. D.K. Park, S.D. Kim, S.H. Lee, J.G. Lee, Copyrolysis characteristics of sawdust and coal blend in TGA and a fixed bed reactor, Bioresource Technology, 101 (2010) 6151-6156.

6. H. Haykiri-Acma, S. Yaman, Synergy in devolatilization characteristics of lignite and hazelnut shell during co-pyrolysis, Fuel, 86 (2007) 373-380.

7. N. Kashimura, J.-i. Hayashi, C.-Z. Li, C. Sathe, T. Chiba, Evidence of poly-condensed aromatic rings in a Victorian brown coal, Fuel, 83 (2004) 97-107.

8. A.G. Collot, Y. Zhuo, D.R. Dugwell, R. Kandiyoti, Co-pyrolysis and co-gasification of coal and biomass in bench-scale fixed-bed and fluidised bed reactors, Fuel, 78 (1999) 667-679.

9. Y.G. Pan, E. Velo, L. Puigjaner, Pyrolysis of blends of biomass with poor coals, Fuel, 75 (1996) 412-418.

10. M.L. Poutsma, Free-radical thermolysis and hydrogenolysis of model hydrocarbons relevant to processing of coal, Energy \& Fuels, 4 (1990) 113131.

11. S.B.L.C.B.M.B.A.A. Jongwon Kim, Coliquefaction of Coal and Black Liquor to Environmentally Acceptable Liquid Fuels, Energy Sources, 21 (1999) 839-847.

12. H. Zhang, B. Dou, H. Zhang, J. Li, C. Ruan, C. Wu, Study on non-isothermal kinetics and the influence of calcium oxide on hydrogen production during bituminous coal pyrolysis, Journal of Analytical and Applied Pyrolysis, 150 (2020) 104888.

13. I. Mian, X. Li, Y. Jian, O.D. Dacres, M. Zhong, J. Liu, F. Ma, N. Rahman, Kinetic study of biomass pellet pyrolysis by using distributed activation energy model and Coats Redfern methods and their comparison, Bioresource Technology, 294 (2019) 122099.

14. H.B. Vuthaluru, Thermal behaviour of coal/biomass blends during co-pyrolysis, Fuel Processing Technology, 85 (2004) 141-155. 